\title{
The Study of Industrial Agglomeration improving Misallocation of Resources
}

\author{
Ji Shu-han, Zhu Ying-ming, Zhang Xin
}

\author{
NanJing University Of Science and Technology, Nanjing 210094, China
}

\begin{abstract}
Keywords: misallocation of resources; industry agglomeration; total factor productivity
\end{abstract}
\begin{abstract}
This paper incorporated industry agglomeration into the misallocation of resources theoretical framework, we constructed improving effect model. By extending the method of Levinsohn and Petrin we calculated the misallocation index in China, the research indicates that $72 \%$ industries are inadequate capital allocation and 69\% are excessive labor allocation, most of capital-intensive industries have configuration phenomenon of excess capital allocation, at the same time, labor-intensive industries are mostly capital inadequate, the lack of labor allocation occurred in the technology-intensive industries; The improvement of agglomeration mainly through the capital threshold and labor structure effect on misallocation. They can create synergies to improve excessive capital allocation and inadequate labor allocation, the elastic coefficient are 0.0845 and 0.013; But industrial agglomeration will do harm to inadequate capital allocation and excessive labor allocation, the elastic coefficient are 0.0280 and 0.0214 ; The capital threshold and labor structure can also have an effective role in misallocation of resources. Through subregional study we found that industry agglomeration in the Eastern region has a better effect, but it has a wider range of improvement in the Midwest part of China. The regional conclusion provided evidences for China's industrial layout, improving resource utilization efficiency and balancing regional development.
\end{abstract}

\section{Introduction}

The research on misallocation of resources is represented by the study conducted by Hsieh and Klenow (2009) ${ }^{[1]}$ on China and India, which constructed a theoretical framework for calculating the indexes of misallocation of resources and estimating the productivity gaps. Utilizing this framework, Dollar and Wei (2007) ${ }^{[2]}$ studied 12,400 enterprises in China and found that China's GDP could be improved by $5 \%$ without any increase of input provided that capital distortion was alleviated. All factors in the economy may generate equal marginal products, but they can still improve the output through reallocation of these factors (Banerjee and Moll, 2010) ${ }^{[3]}$. Chene and Hu (2013) ${ }^{[4]}$ believed that the growth of China's manufacturing industry had been always driven by the input of numerous inexpensive factors, but its actual output was 15\%-20\% lower since the price distortion of factors led to the misallocation of resources among industries. For special historical and practical reasons, China faces a great number of unique distortions, e.g. government supports to state-owned enterprises, priority of credit loan to state-owned enterprises, distorted labor and resource prices, which worsen the misallocation of resources jointly (Jin et al., 2015) ${ }^{[5]}$. Financial subsidy, financial repression, and administrative barrier to entry into market exert a significant effect on the misallocation of resources within industries, while the misallocation of resources between industries is dramatically affected by labor mobility control and financial suppression (Han and Zheng, 2014) ${ }^{[6]}$. Due to these distortions, misallocation of resources appears to be severer in China than this phenomenon in other countries with well-developed market economy. At present, China's economy has entered a New Normal. Considering the economic development law of the New Normal and the domestic economic structure, industrial transformation and upgrading has dominated the economic development of China during the "superposition of three periods", so it should be combined with reasonable structure while unreasonable structure must be adjusted by conducting the structural adjustment on the supply side. Meanwhile, one of the key objectives in the structural adjustment on the supply side is to understand the misallocation of resources and eliminate the excess production capacity, which is of great significance to changing the development focus of the New Normal from high growth rate to efficient and high-quality growth.

The study on misallocation of resources particularly addresses two aspects, i.e. capital 
misallocation and labor misallocation. With regard to capital misallocation, some scholars have found that excessive investment happens more often in such industries with lower concentration ratio, larger percentage of state-owned enterprises, lower threshold for entry and exit, and higher level of reliance on the central and western regions, so these industries face higher degree of capital misallocation (Zhang, 2013) ${ }^{[7]}$. Capital misallocation causes the loss of resource allocation efficiency, which affects the total factor productivity noticeably and results in the decrease of $2.6 \%$ in the total factor productivity. In the meantime, capital misallocation creates a large gap between actual output and potential output, and actual output takes up only 70\%-89\% of potential output (Wang and Yuan, 2014) ${ }^{[8]}$. As revealed in the study on labor misallocation, labor allocation is not promising either, as the unbalanced mobility of labor in different regions worsens the imbalance of economic development between regions in China (Pan and Du, 2010) ${ }^{[9]}$. According to the calculation by Yuan and Xie (2011) ${ }^{[10]}$, labor misallocation ranges between $2 \%-18 \%$, which is gradually widening. Mobility barrier of factors and misallocation of resources have not only affected the total economic output of short term as well as its proportion, but also determined the structure of long-term economic output (Cao and Lou, 2011) ${ }^{[11]}$. Domestic scholars have conducted extensive studies on the existing capital and labor misallocation in China in terms of region and industry, but they always treat misallocation of resources as a separate concept, and fail to extensively explore its connotations. By taking such approaches as estimation of output gap, they have analyzed how misallocation of resources obstructs the economic development and all kinds of factors causing misallocation, but have never expanded the study on the methods for alleviating the misallocation of resources. Hence, this paper intends to delve into the connotations of the misallocation of resources and find out the solution for misallocation of resources.

In the study on the misallocation of resources, it is necessary to find out how to alleviate the misallocation of resources. In the existing literature, there is an attitude that industry agglomeration can alleviate the misallocation of resources. For instance, in his classical work Principles of Economics, Marshall put forth three externalities of industry agglomeration. Among them, "labor market pooling" implied that labor allocation could be optimized by sharing the labor market for the benefits of enterprises and workers. Fan and Shi (2006) ${ }^{[12]}$ explored the influence of industry agglomeration on labor productivity, and claimed that the progressive increase of returns to scale in non-agricultural industries fuels industry agglomeration, and enhances the labor productivity of a region, so as to exert a lasting effect on the gap between regions. Sheng and Wang (2013) ${ }^{[13]}$ argued that industry agglomeration acts on the development of formal and informal finance to help further get rid of the financial barriers in the development course of enterprises. These ideas have been introduced in some studies, but there is still no study on how well industry agglomeration can alleviate the misallocation of resources. Under such circumstances, an attempt is made in this paper to present this study. In this paper, a theoretical framework is constructed on the basis of the theory of misallocation of resources introduced by Hsieh and Klenow (2009). After adding the factors of industry agglomeration into the theoretical framework, misallocation of resources is further divided into insufficient allocation of resources and excessive allocation of resources to analyze the mechanism and effect for alleviating the misallocation of resources through industry agglomeration on this basis.

\section{Theoretical Model}

\section{Basic Hypotheses}

Borrowing the hypothesis on people in the study on competition by Hotelling (1929) ${ }^{[15]}$, and considering the classification of capital by Ruan $(2008)^{[16]}$, the hypotheses regarding social capital are set up as follows:

(1) The capital of enterprise investment $K$ is divided into indirect capital and direct capital. If exceeding the threshold for investment, any individual can directly take part in enterprise investment, i.e. direct investment. If the individual does not have enough money to reach the threshold, he has to make an investment through financial market, i.e. indirect investment. (2) In a 
capital society, everyone owns different amounts of capital $K_{i}$, and $K_{i} \in[0,1]$ is arranged in terms of people. To simplify the capital calculation, this paper hypothesizes the sequence of people $P$ is subject to uniform distribution as shown in Fig. 1. (3) In different industries, there is always a threshold for investment $F, 0<F(h)<1$, and $F$ is the decreasing function of the degree of industry agglomeration $h$. When the degree of industry agglomeration increases, minimum marginal capital decreases less and less dramatically, $F^{\prime}(h)<0, F^{\prime \prime}(h)>0$. (4) If the threshold is closely related to capital investment, the enterprises with higher investment will receive higher rate of return on capital (Baumol, 1982) ${ }^{[18]}$. Entrepreneurs having more capital tend to invest the capital into the industries with higher rate of return on capital, e.g. new high technology with high threshold, and manufacturing of high-end equipment, so their capital becomes direct capital. Meanwhile, some people have capital lower than the capital threshold, so they have to invest it into the capital market, generating indirect capital. Capital misallocation is originated from the distortion of financial market, so it can be hypothesized that misallocation happens to indirect capital but not to direct capital.

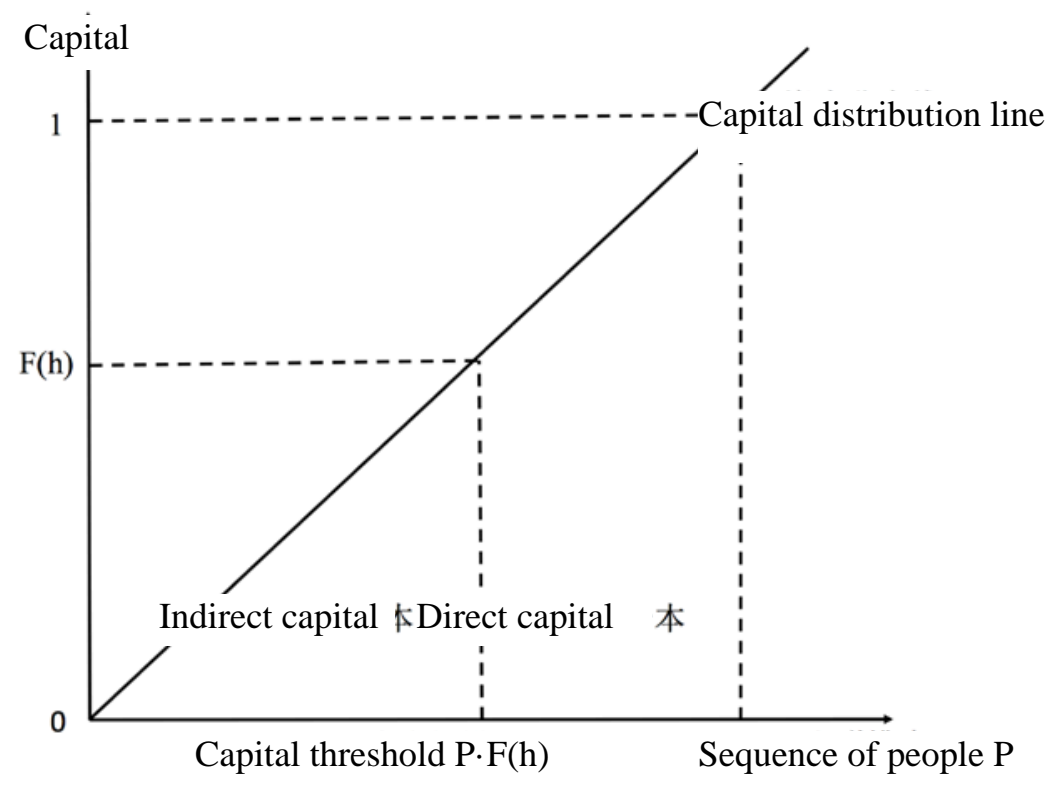

Fig. 1 Distribution of capital owned by people

Data Source: Sorted out by the author

On the basis of the framework constructed by Hsieh and Klenow (2009) ${ }^{[1]}$ for the misallocation of resources, it is further assumed that the production function does not vary in an industry, but varies between industries. In all industries, production relies on capital $K$ and labor $L$ as the factors, and all enterprises in any industry are price takers. In this case, enterprises face distorted prices, which are revealed in the ad valorem tax: $\tau_{K}$ and $\tau_{L}$ denote the distorted "taxes" of such two taxes in the industry $i$. In an economic society, according to the principles of market equilibrium, if $\boldsymbol{\tau}>\mathbf{0}$, the price of a resource is overestimated as there is short supply in the market; if $\boldsymbol{\tau}<\mathbf{0}$, the price is underestimated due to excessive resources. Considering the above hypothesis, the total capital $K$ is divided into indirect capital $K_{j}$ and direct capital $K_{z}$. When capital misallocation happens in the investment of indirect capital, the misallocation index is $\tau_{K}$. According to the hypothesis of rational man, direct investors always choose investing in the enterprises with the highest profits, so there is not misallocation. The triangular area in Fig. 1 stands for the total social capital, so it is deduced that:

$$
\begin{gathered}
K_{z}=\frac{1}{2}[1+F(h)](P-P \cdot F(h)), \quad K_{j}=\frac{1}{2} P \cdot F^{2}(h) \\
K_{z}+K_{j}=K_{i}
\end{gathered}
$$

Secondly, according to the studies on the relationship between labor and division of work by Feenstra and Hanson (1996) ${ }^{[21]}$ and Anderton and Breton (1999) ${ }^{[22]}$, labors $L$ are categorized into skilled workers $L_{j}$ and unskilled workers $L_{f}, \frac{L_{j}}{L_{f}}=\theta$, in which $\theta$ reflects the demand for 
technology in the industry. The higher degree of industry agglomeration, the higher value of $\theta$, i.e. $\theta(h)^{\prime}>0, \theta(h)^{\prime \prime}<0$. The misallocation index is $\tau_{L}$.

Hence, the enterprises in the industry $i$ face the distorted prices of capital $K$ and labor $L$, i.e. $\left(1+\tau_{k i}\right) p_{K},\left(1+\tau_{l i}\right) p_{L}$, in which $p_{K}$ and $p_{L}$ are the price level of two factors under the competitive conditions. It is assumed that the enterprises in the industry $i$ have a production function. To simplify the analysis, it is also assumed that this production function has unchanged returns to scale, i.e. $\beta_{k i}+\beta_{l i}=1$.

\section{Model Construction}

On the basis of the previous hypothesis, the production function of the industry $i$ is constructed as follows:

The profit function is as follows:

$$
y_{i}=T F P_{i} K_{i}^{\beta_{K i}} L_{i}^{\beta_{L i}}=T F P_{i} K_{i}^{\beta_{K i}} L_{i}^{1-\beta_{K i}}
$$

$$
\pi=p_{i} y_{i}-p_{K} K_{i}-p_{L} L_{i}
$$

As revealed above, $\quad p_{k} K_{i}=\frac{1}{2} p_{k}\left\{[1+F(h)]\left(P-P^{*} F(h)\right)+\left(1+\tau_{k}\right) P^{*} F^{2}(h)\right\}$, and Fig. 1 shows $K_{i}=\frac{1}{2} P$, so there is:

$$
\pi=p_{i} y_{i}-p_{K}\left[1+\tau_{K i} F^{2}(h)\right] K_{i}-p_{L}\left(1+\tau_{L i}\right) L_{i}
$$

During the maximization of profit, there is:

$$
\begin{gathered}
\frac{\partial \pi}{\partial K_{i}}=T F P_{i} \beta_{K i} p_{i} K^{\beta_{k i}-1} L^{1-\beta_{k i}}-\left[1+\tau_{k i} F^{2}(h)\right] p_{K}=0 \\
\frac{\partial \pi}{\partial L_{i}}=T F P_{i}\left(1-\beta_{K i}\right) p_{i} K_{i}^{\beta_{k i}} L_{i}^{-\beta_{k i}}-\left(1+\tau_{l i}\right) p_{L}=0
\end{gathered}
$$

It is obtained that:

$$
\begin{gathered}
\left\{\frac{L_{f}\left[1+\theta_{i}(h)\right]}{K}\right\}^{1-\beta_{K i}}=\frac{\left[1+\tau_{K i} F^{2}(h)\right] p_{k}}{T F P \beta_{K i} p_{i}} \\
\left\{\frac{L_{f}\left[1+\theta_{i}(h)\right]}{K}\right\}^{-\beta_{K i}}=\frac{\left(1+\tau_{L i}\right) p_{l}}{T F P\left(1-\beta_{K i}\right) p_{i}}
\end{gathered}
$$

Compared with Equations (8) and (9), the correlation between $\tau_{K}$ and $\tau_{L}$ is represented as follows:

$$
\tau_{L i}=\frac{\left[1+\tau_{K i} F^{2}(h)\right] p_{k}}{\left\{\frac{L_{f}\left[1+\theta_{i}(h)\right]}{K}\right\} p_{l}}-1
$$

As revealed in Equations (8) and (9), labor structure $\theta$ is correlated positively with the index of capital misallocation $\tau_{K}$, and negatively with the index of labor misallocation $\tau_{L}$. Equation (10) shows that $\tau_{L}$ increases with $\tau_{K}$, capital threshold $F$ negatively relates to $\tau_{K}$, and its correlation with $\tau_{L}$ is affected by $\tau_{K}$. According to the definition of misallocation index, the closer to the zero graduation line, the lower degree of misallocation. There is insufficient allocation when it is above the zero point, or excessive allocation when it is below the zero point. The correlations are shown in Fig. 2.

Deduction 1: Labor structure $\theta$ can alleviate misallocation during insufficient labor allocation, but excessive labor allocation may worsen misallocation. However, labor structure $\theta$ affects capital misallocation oppositely. In other words, it can alleviate misallocation during excessive capital allocation, but worsen misallocation when capital allocation is insufficient.

Deduction 2: Capital threshold $F$ alleviates capital misallocation in a mechanism opposite to labor structure $\theta$, and its contribution to alleviation of capital misallocation is affected by the range of capital misallocation. When there is insufficient capital allocation and excessive labor allocation, or excessive capital allocation and insufficient labor allocation, capital threshold can alleviate misallocation. However, misallocation may be worsened by capital threshold if capital and labor are excessively or insufficiently allocated at the same time. 




Fig. 2 Correlations of resource misallocation index with labor structure and capital threshold

Data Source: Drafted by the author

Labor structure $\theta$ and capital threshold $F$ are both affected by the degree of industry agglomeration, so the correlation between industry agglomeration and resource misallocation index is further analyzed as follows:

Let $F(h)^{\prime}=a<0, \theta(h)^{\prime}=b>0$, so the first order derivative is obtained by using the method of derivation through implicit function as follows:

$$
\begin{gathered}
\frac{\partial \tau_{L i}}{\partial(h)}=\frac{-\beta_{K i} b\left(1+\tau_{L i}\right)}{1+\theta(h)} \\
\frac{\partial \tau_{K i}}{\partial(h)}=\frac{1}{F^{2}(h)}\left\{\frac{b\left(1-\beta_{K i}\right)\left[1+\tau_{K i} F^{2}(h)\right]}{1+\theta(h)}-2 a \tau_{K i} F(h)\right\}
\end{gathered}
$$

(1) Labor misallocation: As revealed in Equation (11), the first order derivative is always lower than zero, i.e. $\frac{\partial \tau_{L i}}{\partial(h)}<0$, no matter whether there is insufficient or excessive labor allocation. The calculation shows that the second order partial derivative of labor misallocation against industry agglomeration is $\frac{\partial \tau_{L_{i}}{ }^{2}}{\partial\left(h^{2}\right)}>0$, so labor misallocation index always decreases along with the improving degree of industry agglomeration, and the efficiency of marginal improvement decreases gradually in the meanwhile. Then it is deduced that:

Deduction 3: Industry agglomeration can greatly alleviate misallocation during insufficient labor allocation, but it worsens misallocation when labor allocation is excessive.

(2) Capital misallocation: If capital allocation is insufficient, there is $\tau_{K i}>0$ and $\frac{\partial \tau_{K i}}{\partial(h)}>0$, so agglomeration cannot alleviate capital allocation. Moreover, the second order partial derivative of capital misallocation against industry agglomeration has one point $\frac{\partial \tau_{K i}{ }^{2}}{\partial\left(h^{2}\right)}=0$, so the effect of worsening misallocation diminishes gradually. If there is excessive capital allocation, i.e., $-1<\tau_{K i}<0$, and $\frac{\partial \tau_{k i}}{\partial(h)}=0$, an extreme point exists. Equation (10) is further employed to obtain the partial derivative of labor misallocation index against industry agglomeration, and analyze the mutual effect between capital misallocation index and industry agglomeration as follows:

$$
\frac{\partial \tau_{L i}}{\partial h}=\frac{p_{k}}{\frac{L_{f} p_{l}}{K}} \frac{\left[\frac{\partial \tau_{K i}}{\partial h} F^{2}(h)+2 a F(h) \tau_{K i}\right]\left[1+\theta_{i}(h)\right]-b\left[1+\tau_{K i} F^{2}(h)\right]}{\left[1+\theta_{i}(h)\right]^{2}}<0
$$

Thus, when $\tau_{K i}$ is approximate to -1 , it is obtained $\lim _{\tau_{k \rightarrow} \rightarrow-1} \frac{\partial \tau_{K i}}{\partial h}<0$. As shown in Equation (12), if $\tau_{K i}=0$, there is $\frac{\partial \tau_{K i}}{\partial(h)}>0$. Hence, it is deduced that industry agglomeration worsens the partial derivative of capital misallocation under extreme conditions if capital allocation is excessive, but it can alleviate capital misallocation after exceeding the extreme point.

Deduction 4: Industry agglomeration worsens excessive capital allocation at first, but gradually 
improves it as the degree of industry agglomeration increases. The improvement will last till excessive capital allocation becomes insufficient. At this time, industry agglomeration cannot improve insufficient capital allocation. The correlation between industry agglomeration and misallocation of resources is presented in Fig. 3.

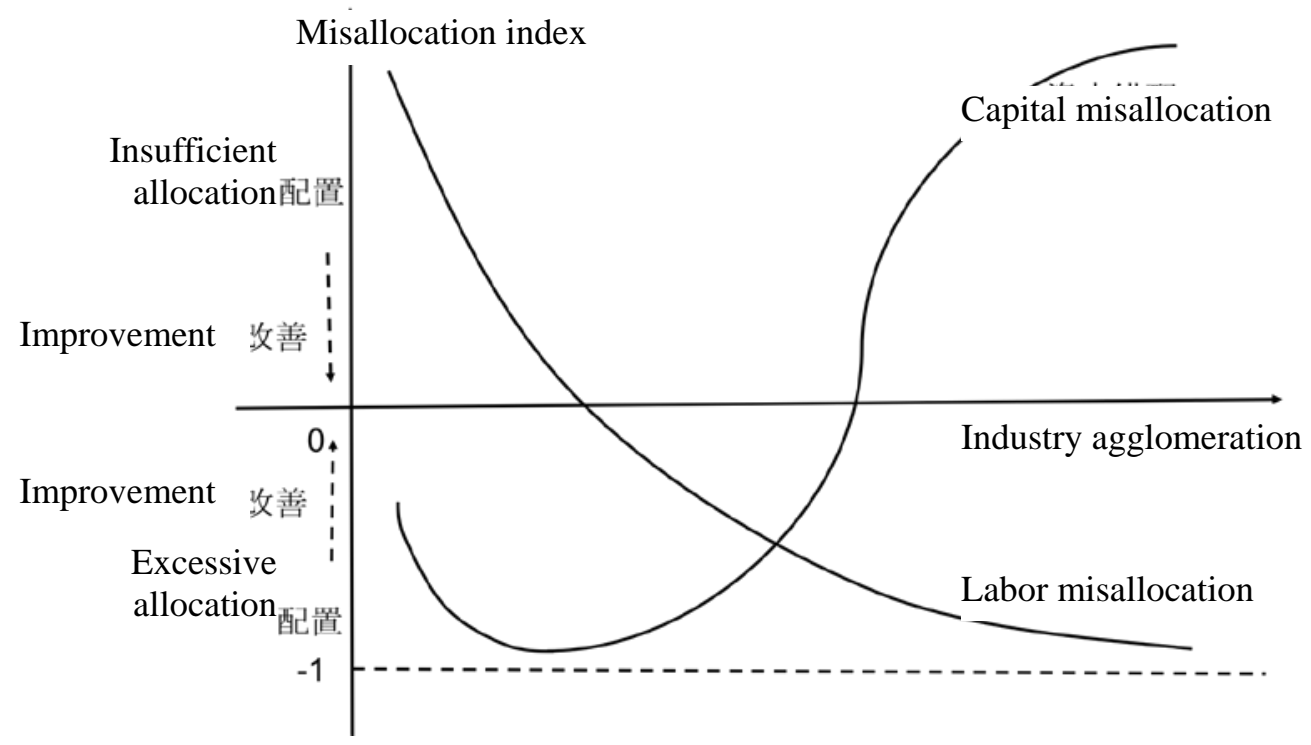

Fig. 3 Correlation between degree of industry agglomeration and index of resource misallocation Data Source: Drafted by the author

\section{Conclusion}

Above all, industry agglomeration has both positive and negative economic effects. With regard to positive effect, it can alleviate the misallocation of resources, while the labor structure and capital threshold affected by agglomeration can also alleviate the misallocation of resources significantly by improving the "efficiency of resource allocation": (1) Industry agglomeration can lower the barrier to entry for enterprises, and guide direct capital to high-quality enterprises, so as to reduce the capital misallocation resulting from the increase of financing cost due to less developed financial system. (2) Industry agglomeration can facilitate labor mobility and increase the number of skilled workers in the agglomeration area, so as to achieve more reasonable labor allocation and alleviate labor misallocation. With its "effect on resource allocation", industry agglomeration can significantly promote the reasonable allocation of resources in the agglomeration area, alleviate the misallocation of resources, and facilitate the structural upgrading of industry. However, the crowding effect caused by industry agglomeration may worsen the misallocation of resources, and cause a number of problems such as environmental pollution, capital spillover, and increasing cost, which force enterprises to relocate, so the degree of agglomeration is lowered to alleviate the misallocation of resources eventually.

The policies released by China after starting the implementation of the reform and opening up policy have clearly demonstrated the importance of the correlation between industry agglomeration and misallocation of resources to economic development. Before the 1990s, China focused more on the improvement of economic efficiency in the regional development policies, and the Central Government particularly implemented the unbalanced development strategy centering on the eastern coastal region. At that time, China achieved very rapid macroeconomic growth, but regional gap was gradually widened along with the economic development, so "polarization effect" became more and more noticeable, and was accompanied by lots of social issues. For this reason, the policies had been gradually changed from unbalanced development with the priority to efficiency to regional coordinated development with equal attention to efficiency and equality. Hence, the Central Government had put forward and implemented the strategies for balanced and coordinated development, i.e. "Development of the Western Regions", "Revitalization of the Old Industrial Bases in Northeast China” and “Promoting the Rise of the Central Region”, in 1999, 2003 and 2005 
respectively, and attached importance to the "diffusion effect" of industry agglomeration on the allocation of resources. The income gap between regions started decreasing in 2004. Additionally, the trend of industry agglomeration in coastal regions began slowing down, while the misallocation of resources in coastal regions was gradually improved. Nevertheless, misallocation of resources is still a strong barrier against economic development in China. Actually, misallocation of resources originates from unreasonable supply of capital and labor. Considering such problems in China as unreasonable capital allocation, excess production capacity in some regions, lower efficiency of resource utilization, lower average educational level of labors, excessive concentration in distribution, and multiple barriers against mobility, the reform on the supply side of resources is needed to alleviate the misallocation of resources.

\section{References}

[1] Hsieh,C. and P.Klenow, Misallocation and Manufacturing TFP In China and India. Quarterly Journal of Economics, 2009, 124(4), 1403-1448.

[2] Dollar,D., and S.Wei, Das(Wasted) Kapital: Firm Ownership and Investment Efficiency in China. NBER Working Paper, No.13103, 2007.

[3] Banerjee,A., and B.Moll, Why Does Misallocation Persist?. American Economic Journal, 2010, 2(1), 189-206.

[4] Chen Yongwei and Hu Weimin. Distortions, misallocation and losses: theory and application. China Economic Quarterly, 2011(4), 1401-1422.

[5] Han Jian and Zheng Qiuling. How does government intervention lead to regional resource misallocation - based on decomposition of misallocation within and between industries. China Industrial Economics, 2014(11), 69-81.

[6] Jin, Laiqun, Lin Jinzhong and Ding Shishi. Effect of administrative monopoly on resources misallocation caused by ownership differences. China Industrial Economics, 2015(4), 31-43.

[7] Zhang Pei. Study on misallocation of resources between industries in China's industrial sector. Review of Investment Studies, 2013(6).

[8] Wang Linhui, and Yuan Li. Was capital misallocation an important factor for loss in total factor productivity. Statistical Research, 2014, 31(8), 11-18.

[9] Pan Yue and Du Xiaomin. Labor mobility, industrialization process and regional economic growth. The Journal of Quantitative \& Technical Economics, 2010(5), 34-48.

[10]Cao Yushu and Lou Dongwei. Misallocation, structural change and China's economic transition. China Industrial Economics, 2012(10), 5-18. 